\title{
La gestión ética en los colegios públicos nocturnos-académicos del sistema educativo costarricense, desde la mirada del personal administrativo-docente
}

Adrián Solano Castro* Ingrid Monge Rodríguez ${ }^{* *}$

Olman Bolaños Ortiz***

Warner Ruiz Chaves****

\author{
* Profesor de la Escuela de Ciencias de la Educación, UNED, Costa Rica; \\ asolano@uned.ac.cr \\ ** Profesora de la Escuela de Ciencias de la Educación, UNED, Costa Rica; \\ imonge@uned.ac.cr \\ ** Profesor de la Escuela de Ciencias de la Educación, UNED, Costa Rica; \\ olbolanos@uned.ac.cr \\ *** Profesor de la Escuela de Ciencias de la Educación, UNED, Costa Rica; \\ wruiz@uned.ac.cr
}

Recibido: 09 de agosto del 2018 Corregido: 29 de agosto del 2018 Aceptado: 03 de octubre del 2018

\begin{abstract}
Resumen
Este documento presenta los resultados de una investigación basada en la encuesta realizada a un grupo de profesionales administrativo-docentes de colegios nocturnos académicos del sistema público costarricense. El estudio recuperó opiniones con respecto a la ética en la gestión de los centros educativos. Entre los principales resultados se encontró que las percepciones acerca del conocimiento de la gestión ética inciden en el quehacer práctico del administrador de centro educativo, pues es donde se concretan y donde el mismo funcionario lo evidencia. Por ende, situaciones vinculadas con la transparencia, el consenso, el diálogo, el respeto, el disenso, entre otros, se reconocen y están presentes en la gestión del centro. No obstante, hay que fortalecer la transparencia institucional y el desarrollo profesional para afianzar los saberes existentes en los administradores educativos sobre la gestión ética de su centro educativo.
\end{abstract}

Palabras clave: Educación, ética, deontología, gestión educativa, colegios estatales.

\section{Abstract \\ Ethical management in public night-academic high schools of the costa rican educational system, from the view of the administrative and teacher personnel}

This document presents the results of a research based on the survey applied to a group of administrative-professionals of night academic highschools of the Costa Rica educational public system. The study recovered opinions about the ethic on the management of schools. A total of 51 workers of night schools participated in this study (one per each institution). Among the main results, it was found that the perception about the knowledge of the ethical management, affects the practical task of the administrator of the school, because it is where they are stablished and it is also where the 
workers can evidence it, due to the knowledge they have. Therefore, situations related to transparency, consensus, dialogue, dissent, among others, are known and included in the schools managemente. However, institutional transparency and professional development must be strengthened in order to consolidate the existing knowledge in educational administrators about the ethical management of their educational institution.

Key words: Education, ethics, deontology, education management, state high schools.

\section{INTRODUCCIÓN}

Los colegios nocturnos en Costa Rica constituyen una oferta de la educación para jóvenes y adultos por parte del Ministerio de Educación Pública (MEP) desde 1950.

Actualmente, existen 54 colegios y al igual que en las restantes modalidades del sistema educativo aplica lo que Martín-Moreno (2007) señala respecto de la multifuncionalidad de centros educativos: su trabajo no se centra exclusivamente en actividades académicas, sino también en el desarrollo de actividades vinculadas con el trabajo social y la acción comunitaria, por lo que constituyen espacios de intervención habitual para otras áreas, además de la educación.

Desde esta perspectiva, abordar el tema de la gestión ética es vital para comprender el entramado que se presenta en las instituciones y que incide en la administración del centro educativo y la comunidad que en él se desenvuelve. Siendo esencial la administración educativa, como instancia articuladora y coordinadora de todos los procesos que en el contexto confluyen.

Por otro lado, la ética en la gestión se relaciona con el impacto de los servicios educativos, que reflejan las actuaciones de los funcionarios públicos. Así, se presenta la necesidad de caracterizar el comportamiento ético de los administradores educativos: la eficiencia en sus funciones, la claridad y la transparencia en sus acciones.

Diversos autores recurren a la raíz griega "ethos" para dar un concepto de ética; con base en ella es que se refieren a la ética como uso o costumbre. Guillén (2006) define la ética como un comportamiento que contribuye a las cualidades propias del ser humano, que se relaciona con las acciones que de alguna manera provocan que la persona sea digna de confianza. Agrega que la ética busca la excelencia humana por medio del aprendizaje de las acciones que se incorporan, como un hábito o costumbre respecto de la dirección que deben llevar las mismas, es decir, el norte que orienta el proceder en procura de un bien posible.

La ética estudia el comportamiento humano. Si se desea visualizarla dentro de un referente, se puede hablar de ética aplicada. Hay diversos contextos: el más general es la sociedad, pero también hay otros ambientes, como la herencia cultural y familiar o la organización donde se realiza el ejercicio profesional. Lo anterior referido a que el comportamiento humano no se presenta en el vacío, sino que pertenece a un amplio campo de acción. Siempre el objeto material de la ética es el comportamiento, pero el ámbito donde se desarrolla ese comportamiento es el que Guillén (2006) llama objeto formal.

Bajo esta perspectiva, el abordaje para la organización educativa en la sociedad actual se encuentra en un proceso de transición, en palabras de Vásquez (2013):

La concepción tecnocrática ha ensombrecido la dimensión ética, teniendo como efecto la exclusión de las cuestiones éticas o, en el mejor de los casos, son tratadas como un asunto técnico. Y es lo 
que se está haciendo al establecer competencias éticas para la dirección. Por tanto, la ética tiene que ocupar un lugar central y visible cuando se aborda el tema de la dirección escolar, porque sin aquella no podemos comprender la expresión práctica y situada de ésta. La dirección va más allá de funciones, tareas y competencias. Lo complicado y lo difícil de la dirección no reside expresamente en lo que hay que hacer sino en lo que la persona piensa, siente y valora ante lo que tiene o debe hacer (p.84).

Por lo tanto, desde el momento en que se adopta el planteamiento de la acción para la dirección escolar, la ética se convierte en el eje central porque las organizaciones educativas continuamente llevan a cabo acciones. El carácter ético de las acciones se constata, precisamente, en las prácticas para la toma de decisiones que han de afrontarse de forma permanente en la vida organizativa de las instituciones educativas en general.

Esta dimensión de la ética se refiere a la ética profesional, en la cual se debe contextualizar al individuo y sus comportamientos en un quehacer profesional determinado. Enríquez, De la Campa, Valdés, Navarrete, Guillén \& Lemus (2014), definen la ética profesional como "la que determina los deberes mínimamente exigibles a los profesionales en el desempeño de su actividad (ejercicio de una profesión)" (p. 8). De manera que una visión de gestión ética del administrador educativo plantea la necesidad de establecer una gestión basada en principios y valores que permitan desarrollar una relación ética y transparente con los actores de la comunidad educativa. Tal como lo manifiesta Vásquez (2013):

La ética, entonces, pasa a ocupar un lugar destacado en la compresión de la dirección; toda acción tiene un valor ético. Lógicamente, es mucho más fácil y menos comprometido abordar la dirección desde aspectos técnicos y desde parámetros competenciales, que desde cuestiones que tienen que ver directamente con la ética (intereses, conflictos, toma de decisiones, poder [...] (p.82).

Rojas (2012) se refiere a la acción del gerente o administrador dentro de la organización desde un papel ético como ente social, es decir, con su comportamiento ante los niveles de mando superior, es el referente de la ética que existe dentro de la organización y sus miembros. Si el administrador educativo es considerado por la jefatura y por el personal a su cargo como un modelo ético, entonces en ambos sentidos se toman mejores decisiones en cuanto a dilemas éticos que se pueden presentar dentro de la organización.

Asimismo, Zeledón (2011) hace un resumen de las habilidades o características del administrador que, de contar con ellas, podría tener un mejor desempeño ético en sus funciones.

- El deseo de influir, como buen líder, en otras personas para lograr alcanzar los resultados que espera dentro de su gestión educativa.

- Ser promotor de un buen clima organizacional que le facilite el trabajo en conjunto con los miembros de la comunidad educativa, hacia el logro de metas comunes.

- Que posean aptitudes de comunicación, para que de manera clara y enfocada en las acciones por realizar, pueda expresarse adecuadamente en cualquiera de sus formas (oral, escrita, gestual, corporal), negociando de manera asertiva y evitando conflictos.

- Ser empático, para poder comprender a su equipo de trabajo en el cumplimiento del quehacer profesional.

- Ser moralmente íntegro, para merecerse la confianza de sus colaboradores y mantener buenas relaciones interpersonales, de acuerdo con los estándares éticos socialmente aceptados. 
- Desempeñar su gestión responsablemente, de la mejor manera posible, con un estilo propio que demuestre originalidad y creatividad; congruente con lo que pide a su equipo de trabajo.

- Mostrar actitudes de respeto y reconocimiento hacia el trabajo de los otros, y humildad para reconocer cuando debe mejorar su gestión.

- Ser consciente de la misión, visión y valores organizacionales; conocerlos y aplicarlos, reflejarlos y fomentarlos en el centro educativo.

\section{ASPECTOS METODOLÓGICOS}

La investigación consistió en un estudio basado en encuesta. Se trabajó con personal docente administrativo de 51 colegios académicos nocturnos del sistema educativo público costarricense, dentro de los cuales se destaca personal director, subdirector, asistente de dirección y auxiliar administrativo. El cuestionario se aplicó de manera digital utilizando el programa Lime Survey@.

Para el desarrollo del estudio se empleó una versión adaptada por el equipo de investigación del Instrumento de Percepción de la Gestión Ética, presentado por el Programa "Eficiencia y Rendición de Cuentas en Colombia" en su modelo de gestión ética para entidades del Estado.

Se trabajó con seis categorías o componentes referidos a la ética en la gestión de organizaciones educativas. Las categorías son: construcción y aplicación del referente ético, principios y valores éticos en la institución, liderazgo de los directores en la gestión ética, relaciones con los profesores de la institución, relaciones con la comunidad y relaciones con los estudiantes. Una vez que se recopiló toda la información, se procedió al análisis estadístico descriptivo y al uso del mismo software Lime Survey® para la realización de las figuras y organización de los cuadros.

\section{RESULTADOS}

En términos generales, se evidencia que existe la gestión ética en los centros educativos de secundaria académica nocturna de Costa Rica.

La sociedad global y cambiante en que se vive, requiere de acciones que no solo permitan estar actualizados en temas educativos, sino impulsar nuevas prácticas colectivas que garanticen una gestión transparente, ética, organizada según las necesidades de la comunidad educativa en la que se trabaje.

Para iniciar, es importante retomar que para Pérez y otros (2006), la "Ética es el conjunto de principios, valores y normas del fuero interno que guían las conductas de las personas en su interacción social ( $p$. 25)", por ello es una necesidad, en términos de respeto y consideración, que cuando existe una relación con "el otro" se desarrolle en el marco de un conjunto de normas que legitima la relación. Las personas que conforman la comunidad educativa de los centros educativos nocturnos, socializan, conviven, logran consensos y evidencian disensos; toda la interacción permite reafirmar que los seres humanos somos sociales por naturaleza; razón por la cual el vincularnos con "el otro" hacen que la noción de ética se evidencie.

En este sentido, la relación configura un mundo social donde las percepciones de cómo conducirse y cómo se visualizan las actuaciones, resulta necesario conocerlas. Por tanto, la primera parte de los resultados expuestos señalan cómo el administrador de centro educativo percibe los principios y valores éticos personales. Nótese los resultados de la siguiente tabla: 
TABLA 1

Percepciones de los administradores de centro educativo (CE) sobre los principios y valores éticos que practican

\begin{tabular}{|c|c|c|c|c|c|}
\hline $\begin{array}{c}\text { Escala / } \\
\text { Elemento consultado }\end{array}$ & $\begin{array}{l}\text { Prevalece el } \\
\text { interés general } \\
\text { sobre el } \\
\text { particular }\end{array}$ & $\begin{array}{l}\text { Integridad, honestidad, } \\
\text { responsabilidad y } \\
\text { equidad son valores } \\
\text { que le caracterizan }\end{array}$ & $\begin{array}{c}\text { Evita conductas que } \\
\text { le desprestigien } \\
\text { personal } \\
\text { y profesionalmente }\end{array}$ & $\begin{array}{c}\text { Cuando administra } \\
\text { el CE considera que } \\
\text { no es malo } \\
\text { recibir dádivas }\end{array}$ & $\begin{array}{l}\text { El accionar se } \\
\text { rige porque la } \\
\text { educación es } \\
\text { un bien público }\end{array}$ \\
\hline Muy en desacuerdo & $3,92 \%$ & $0,00 \%$ & $0,00 \%$ & $76,47 \%$ & $0,00 \%$ \\
\hline $\begin{array}{l}\text { Más en desacuerdo que } \\
\text { de acuerdo }\end{array}$ & $5,88 \%$ & $1,96 \%$ & $0,00 \%$ & $3,92 \%$ & $1,96 \%$ \\
\hline $\begin{array}{l}\text { Ni de acuerdo ni en } \\
\text { desacuerdo }\end{array}$ & $1,96 \%$ & $1,96 \%$ & $3,92 \%$ & $1,96 \%$ & $3,92 \%$ \\
\hline $\begin{array}{l}\text { Más de acuerdo que en } \\
\text { desacuerdo }\end{array}$ & $3,92 \%$ & $1,96 \%$ & $5,88 \%$ & $1,96 \%$ & $7,84 \%$ \\
\hline Muy de acuerdo & $84,31 \%$ & $94,12 \%$ & $90,20 \%$ & $15,69 \%$ & $86,27 \%$ \\
\hline
\end{tabular}

Fuente: Elaboración propia a partir de encuesta aplicada a personal administrativo docente. de colegios nocturnos académicos del sistema educativo costarricense, 2017.

En relación con lo observado en la tabla 1 nótese que, en términos generales, las percepciones de los administradores de centros educativos y otros funcionarios administrativos coinciden en la escala de "Muy de acuerdo" por cuanto los elementos consultados inciden de manera directa en el quehacer que como directivos ejercen en su cargo. Es importante resaltar que la mayoría de las indicaciones diferentes a la escala supracitada fueron anotadas por los funcionarios subdirectores y/o auxiliares, según la revisión manual que se hiciera de la información recolectada en el instrumento.

Ahora bien, si el peso relativo de los subdirectores y auxiliares representa un aproximado al $12 \%$ de la población, eso implica que, en el primer elemento consultado, una parte del personal considera que no necesariamente pesa el interés general sobre el particular, pues un $15,69 \%$ así lo expresa. Como lo manifiesta Vásquez (2013):

La ética, entonces, pasa a ocupar un lugar destacado en la compresión de la dirección; toda acción tiene un valor ético. Lógicamente, es mucho más fácil y menos comprometido abordar la dirección desde aspectos técnicos y desde parámetros competenciales, que desde cuestiones que tienen que ver directamente con la ética (intereses, conflictos, toma de decisiones, poder [...]. (p.82)

Lo anterior evidencia que existe una necesidad de comprender que la administración de un centro educativo, si bien es cierto, genera compromiso e intereses particulares, su gestión debe ser para la colectividad.

Por otra parte, resulta interesante cuando se consulta acerca de las dádivas, pues solo un $76,47 \%$ de los informantes consideran que no procede recibirlas. Al respecto, Pérez (2006) señala:

al estar a cargo de algo que es de índole pública o colectiva que va más allá de su ámbito individual, es evidente que el servidor público no se representa a sí mismo en el ejercicio de sus funciones, sino que representa a otros. (p. 31)

Del mismo modo, la Ley Contra la Corrupción y el Enriquecimiento llícito señala que un acto de corrupción es "[...] la aceptación, directa o indirectamente, por un funcionario público o una persona que ejerza funciones públicas, de cualquier objeto de valor pecuniario u otros beneficios como dádivas, favores, premios, promesas o ventajas para sí mismo" (2004, p. 2). Esta situación evidencia la necesidad 
de seguir reforzando controles, concientizando a las personas y generando procesos de desarrollo profesional orientados a lograr mayor conocimiento de la administración pública, en función de la gestión de centros educativos.

Ahora bien, se consulta sobre la existencia de un código de ética en el colegio nocturno, al respecto, la figura uno evidencia que en la mitad de los centros educativos que participaron se cuenta con un código de ética. Esto considerando que el rango "muy de acuerdo" corresponde a un sí definitivo.

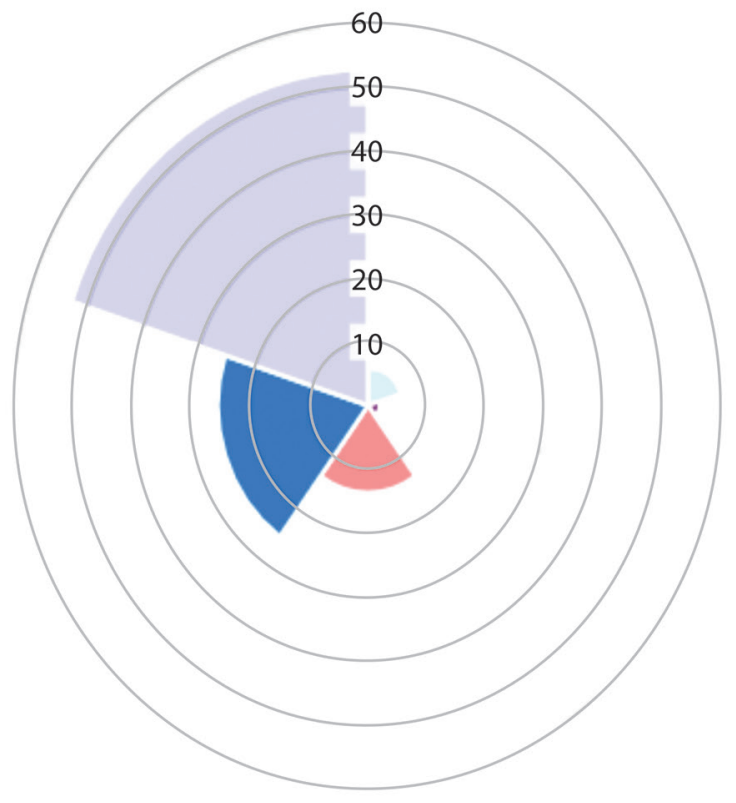

Muy en desacuerdo

Más en desacuerdo que de acuerdo

Ni de acuerdo ni en desacuerdo

Más de acuerdo que en desacuerdo

Muy de acuerdo

Figura 1. Opinión de los encuestados sobre la existencia de un código de ética en el centro educativo (datos relativos).

Fuente: Elaboración propia a partir de encuesta aplicada a personal administrativo docente de colegios nocturnos académicos del sistema educativo costarricense, 2017.

Contar con un código de ética, en tiempos cambiantes como los actuales, es fundamental. Las instituciones que incluyen manuales de valores éticos para guiar su funcionamiento, así como la socialización a lo interno de la organización, son las que perduran y tienen mayor estabilidad en cuanto a funcionamiento (Cortina, 2004; Orden, 2014). Tal como lo señala Colorado (2016):

Las organizaciones educativas, por su naturaleza y actividad, tienen un espacio diferenciador y especial de acción social diferente a las organizaciones empresariales y privadas. Es clave que se pregunten sobre sus metas y medios para conseguir ser instituciones éticas. Como apunta Lozano (2007), la meta de las organizaciones educativas es aumentar el progreso y la autonomía de las personas, y esto pasa por actuar en esas organizaciones con medios más democráticos, participativos, con espacios de diálogo, de reflexión, etc. (p.3)

El reto es procurar que esta buena práctica sea llevada a cabo por todas las instituciones, de modo que se puedan convertir en centros educativos cuya gestión administrativa se basa en la ética del buen y óptimo funcionamiento público. 
TABLA 2

Aplicación del referente teórico sobre ética en el centro educativo (CE)

\begin{tabular}{|lcc|c|}
\hline \multicolumn{1}{c}{$\begin{array}{c}\text { Escala / } \\
\text { Elemento consultado }\end{array}$} & $\begin{array}{c}\text { Aplicación del código } \\
\text { de ética en el CE }\end{array}$ & $\begin{array}{c}\text { Acompañamiento del } \\
\text { administrador de CE para que } \\
\text { se cumpla el código de ética }\end{array}$ & $\begin{array}{c}\text { Los conflictos se resuelven } \\
\text { según el código de ética } \\
\text { o los valores éticos }\end{array}$ \\
\hline Muy en desacuerdo & $1,96 \%$ & $1,96 \%$ & $0,00 \%$ \\
\hline Más en desacuerdo que de acuerdo & $5,88 \%$ & $5,88 \%$ & $3,92 \%$ \\
Ni de acuerdo ni en desacuerdo & $9,80 \%$ & $23,53 \%$ & $11,76 \%$ \\
\hline Más de acuerdo que en desacuerdo & $29,41 \%$ & $23,53 \%$ & $33,33 \%$ \\
Muy de acuerdo & $52,94 \%$ & $45,10 \%$ & $50,98 \%$
\end{tabular}

Fuente: Elaboración propia a partir de encuesta aplicada a personal administrativo docente de colegios nocturnos académicos del sistema educativo costarricense, 2017.

Los resultados expuestos, vinculados con la primera etapa de construcción y aplicación de un referente teórico y de acuerdo con Zeledón (2011), evidencian una carencia en la construcción y aplicación de un marco teórico en los centros educativos, esto a pesar de que, como se observó en la figura 1,52\% de los centros cuentan con código de ética.

Es importante rescatar en este apartado, que en $52,94 \%$ de los colegios nocturnos participantes se construyó y se aplica un marco ético, situación que a nivel general concuerda con los centros educativos que poseen código de ética, por lo que se podría inferir que a pesar de que existe un documento normativo, su práctica, ejecución e implementación no necesariamente es extendida. Al respecto, Gentili (2000) señala que "la escuela es una agencia moral de fundamental importancia porque es donde se aprenden y se ponen en práctica valores, normas y derechos" (p. 50); así las cosas es necesario que en los centros educativos nocturnos se reflexione acerca de la utilidad del mismo código construido, pues si desde el mismo personal no hay una vivencia, aplicación e implementación, el impacto esperado o lo que se puede pedir a la comunidad educativa no tendría sentido, pues no existe correspondencia entre teoría y práctica.

Por otra parte, parafraseando a Orduna (2000), cuando se realizan procesos de educación en donde intervienen diferentes agentes, se dependerá del papel que ejerzan en ese sistema para poder realizar un aporte exitoso al mismo. En este sentido, cuando se consulta a los directivos de los colegios nocturnos acerca de su acompañamiento para que se cumpla el código de ética, apenas $45 \%$ de los informantes señala que lo hace, mientras que otro $46 \%$ señala que el acompañamiento no es constante (escala "ni de acuerdo ni en desacuerdo más la escala "más de acuerdo que en desacuerdo").

La situación antes expuesta debe llamar a la reflexión a los mismos administradores educativos pues sin su colaboración y acompañamiento no existirá mayor compromiso de otros involucrados.

Por último, en cuanto a la resolución de conflictos en el centro educativo, se consultó si los mismos se resolvían según lo planteado en el código de ética, en términos generales, los directivos de los colegios nocturnos señalan que $51 \%$ de éstos son resueltos a lo interno, mientas que $33 \%$ indican que la mayoría de las situaciones en efecto se solucionan según las normas internas, específicamente el código de ética. Carmona (2015) en una investigación sobre gestión de conflictos en centros educativos (que incluyó un colegio nocturno en la muestra) determinó:

[...] las acciones que desde la dirección se desarrollan para atender situaciones conflictivas laborales [...] son alternativas, diversos estilos y estrategias, que han puesto en marcha para un sano manejo de los centros educativos. Ahora bien, es importante recalcar, como se ha mencionado, que cada centro educativo es distinto por lo que las soluciones lo serán de igual manera. Las acciones 
expuestas son sólo una posible guía para atacar la problemática, está en el director y en la situación como tal, la forma más idónea de manejarlo. Así las cosas, dependiendo del matiz y de la particularidad de la contienda, los directores pueden optar por una estrategia de expansión, contracción, de perder - perder/ganar - ganar, al mismo tiempo que pueden analizar la alternativa de negociar con las partes, de omitir la situación, optar por una posición de mando autoritario o llegar a la solución del problema. (párr. 102)

TABLA 3

Aplicación del referente ético en los funcionarios del centro educativo (CE)

\begin{tabular}{|c|c|c|c|}
\hline $\begin{array}{c}\text { Escala / } \\
\text { Elemento consultado }\end{array}$ & $\begin{array}{l}\text { Funcionarios del CE se } \\
\text { abstienen de recibir dádivas }\end{array}$ & $\begin{array}{l}\text { Los funcionarios del CE realizan } \\
\text { sus labores considerando el } \\
\text { interés general sobre el particular }\end{array}$ & $\begin{array}{l}\text { Práctica de la honestidad } \\
\text { y transparencia en los } \\
\text { funcionarios del CE }\end{array}$ \\
\hline Muy en desacuerdo & $7,84 \%$ & $1,96 \%$ & $0,00 \%$ \\
\hline Más en desacuerdo que de acuerdo & $5,88 \%$ & $1,96 \%$ & $3,92 \%$ \\
\hline Ni de acuerdo ni en desacuerdo & $15,69 \%$ & $9,80 \%$ & $1,96 \%$ \\
\hline Más de acuerdo que en desacuerdo & $23,53 \%$ & $41,18 \%$ & $47,06 \%$ \\
\hline Muy de acuerdo & $47,06 \%$ & $45,10 \%$ & $47,06 \%$ \\
\hline
\end{tabular}

Fuente: Elaboración propia a partir de encuesta aplicada a personal administrativo docente de colegios nocturnos académicos del sistema educativo costarricense, 2017.

En relación con el cuadro anterior, se debe destacar la primera columna, la cual se refiere a las dádivas, nótese que apenas $47,06 \%$ asevera estar "muy de acuerdo" con abstenerse de las compensaciones. No obstante, $29,41 \%$ se ubican en el tercer rango (de "ni de acuerdo ni en desacuerdo" a "muy en desacuerdo"), situación que invita a la reflexión pues, aunque sean situaciones que no impliquen dolo o no busquen perjudicar la hacienda pública, legalmente no proceden. Al respecto, La Ley contra la Corrupción y el Enriquecimiento llícito en la Función Pública ( $N^{\circ}$. 8422), en su artículo 20 regula lo relacionado con donaciones y obsequios, del mismo modo el Código Deontológico de COLYPRO (2018), en el artículo 39 sobre no aceptación de dádivas, señala:

La persona colegiada debe abstenerse de recibir cualquier tipo de obsequio, dádiva o regalo de parte de los estudiantes, especialmente cuando la intencionalidad es una retribución en el sentido de lograr favoritismos u obtener objetivos que riñan con la moral y la equidad (s.p.) .

En cuanto a la percepción de privar el interés general sobre el particular, en términos generales, y según el director, los funcionarios lo validan, por cuanto si se suma la escala de "muy de acuerdo" junto con "más de acuerdo que en desacuerdo", otorgan $86,28 \%$ de percepción. En los dos puntos anteriores, al ser percepciones del administrador de centro, acerca de sus funcionarios, es importante ejercer una corresponsabilidad en el recordatorio de la normativa, con el fin de brindar no solo un acompañamiento a su colaborador, sino evitar situaciones en cuanto a procesos administrativos y/o disciplinarios.

Por su lado, en cuanto al rubro "Práctica de la honestidad y transparencia en los funcionarios del CE", podría ser que los administradores educativos de los colegios nocturnos apliquen el "principio de desconfianza sistemática" propuesto por Pereda (2009):

Es un principio de confianza interpersonal, quien confía subordina su juicio a la discreción y al juicio de otra persona o, si se prefiere, a su buena o mala voluntad en la medida en que, literalmente, pone en sus manos algo que considera de valor (párr. 4). 
Así, los directores de centro educativo confían y consideran que sus colaboradores practican la honestidad y la transparencia, pero no en un $100 \%$, tal como lo refleja el cuadro 3, pues siempre el margen de que alguien pueda no "ajustarse" evoca la desconfianza sistemática, generada en espacios donde la interacción con "el otro" es más cercana o más constante. Si se desea contrastar esta propuesta, nótese como llega apenas a 70\% la percepción de director en cuánto las dádivas (sumatoria de "muy de acuerdo" y "más de acuerdo que en desacuerdo"), es decir, utilizando palabras de Pereda (2009) "la confianza siempre es general. Nuestra desconfianza, dudas, sospechas son focales" (párr. 5).

TABLA 4

Percepción del administrador del centro educativo de su liderazgo en gestión ética

\begin{tabular}{|lccc|}
\hline \multicolumn{1}{c}{$\begin{array}{c}\text { Escala / } \\
\text { Elemento consultado }\end{array}$} & $\begin{array}{c}\text { La administración del CE } \\
\text { se realiza con conocimiento, } \\
\text { experiencia y capacidad }\end{array}$ & $\begin{array}{c}\text { La comunicación en } \\
\text { la administración del CE es clara, } \\
\text { efectiva y oportuna }\end{array}$ & $\begin{array}{c}\text { La gestión de la administración } \\
\text { se sustenta en los principios de } \\
\text { equidad, comprensión y respeto }\end{array}$ \\
\hline Muy en desacuerdo & $1,96 \%$ & $0,00 \%$ & $1,96 \%$ \\
\hline Más en desacuerdo que de acuerdo & $0,00 \%$ & $1,96 \%$ & $0,00 \%$ \\
\hline Ni de acuerdo ni en desacuerdo & $1,96 \%$ & $0,00 \%$ & $0,00 \%$ \\
\hline Más de acuerdo que en desacuerdo & $15,69 \%$ & $33,33 \%$ & $13,73 \%$ \\
\hline Muy de acuerdo & $80,39 \%$ & $64,71 \%$ & $84,31 \%$ \\
\hline
\end{tabular}

Fuente: Elaboración propia a partir de encuesta aplicada al personal administrativo docente de colegios nocturnos académicos del sistema educativo costarricense, 2017.

La antepenúltima sección del instrumento aplicado se refiere a la percepción de liderazgo que el directivo de centro educativo tiene de sí mismo en relación con la gestión del centro. Al respecto, habría que indicar que la gestión de un centro educativo es uno de los desafíos que enfrentan los profesionales dedicados a la administración educativa, pues no solo implica conocer de elementos pedagógicos para un adecuado acompañamiento, sino de saberes administrativos para un eficaz y eficiente uso de los recursos institucionales; no obstante, aunado a esto, es fundamental el componente emocional, específicamente el desarrollo personal del directivo, por cuanto la combinación de los tres elementos podría asegurar una gestión de calidad alineada con el marco de la ética.

Por tanto, percibirse como líder no basta para una adecuada gestión, aunque en la tabla 4 la mayoría de los directivos afirma que sí lo son. Es importante, evidenciar conocimiento, capacidad, comunicación, principios morales, equidad, respeto, comprensión, diálogo, consenso, entre otras habilidades que coadyuvan al alcance de los logros comunes. En el caso particular, los directores consultados señalan que $80,39 \%$ y $84,31 \%$, tienen conocimiento / capacidad y sustentan su gestión en equidad, comprensión y respecto. Como señala Pozner (2015):

Gestión implica no sólo disciplina, gestión escolar es en realidad eso que hacen los directivos e implica siempre una tensión entre ética y eficacia. No basta con ser eficaz, también la decisión tiene que ser ética; no basta con administrar la escuela, hay que gobernarla con criterios claros pedagógicos; no basta con el conocimiento teórico, porque ningún libro les va a decir lo que tienen que hacer para los casos que se les presenta en cada una de las escuelas; hace falta estudiar el conocimiento teórico, pero también hace falta recuperar un conocimiento que viene de la práctica, que tiene que ver con los problemas que se nos presentan (p. 23).

Hay un punto que es de resaltar, cuando se consulta sobre la comunicación en la administración del centro educativo, los resultados señalan, según percepción del mismo administrador, que apenas es efectiva (muy de acuerdo) en $64,71 \%$. Sobre el mismo punto se debe aclarar que, aunque $33,33 \%$ señala 
estar "más de acuerdo que en desacuerdo", lo cierto es que en asuntos de este tipo se comunica claramente o no. Rivas (2002), citado por Quero, Mendoza y Torres (2014), señala:

Las organizaciones que están en constante desafío alcanzan a través de la comunicación que las personas identifiquen los procesos administrativos y gerenciales dados, permitiendo una interrelación y feedback para lograr los resultados o señalar cambios; por lo tanto, se hace necesario ver a la comunicación como el eje central de la organización (párr. 3).

Se evidencia que la comunicación clara, efectiva y oportuna es fundamental para el éxito de los procesos administrativos y pedagógicos en un centro educativo, razón por la cual la aspiración de todo directivo debe ser lograr el diálogo con los participantes del hecho educativo.

TABLA 5

Relaciones con el personal del CE en el marco de la gestión ética (datos relativos)

\begin{tabular}{|c|c|c|c|}
\hline Escala / Elemento consultado & $\begin{array}{c}\text { El clima organizacional } \\
\text { permite el desarrollo y bienestar } \\
\text { de los funcionarios }\end{array}$ & $\begin{array}{l}\text { El trato a los funcionarios } \\
\text { es igualitario, sin ninguna } \\
\text { clase de discriminación }\end{array}$ & $\begin{array}{l}\text { Se garantiza la igualdad en } \\
\text { la capacitación, evaluación } \\
\text { y promoción de los funcionarios }\end{array}$ \\
\hline Muy en desacuerdo & $1,96 \%$ & $1,96 \%$ & $1,96 \%$ \\
\hline Más en desacuerdo que de acuerdo & $1,96 \%$ & $0,00 \%$ & $0,00 \%$ \\
\hline Ni de acuerdo ni en desacuerdo & $3,92 \%$ & $0,00 \%$ & $1,96 \%$ \\
\hline Más de acuerdo que en desacuerdo & $31,37 \%$ & $9,80 \%$ & $13,73 \%$ \\
\hline Muy de acuerdo & $60,78 \%$ & $88,24 \%$ & $82,35 \%$ \\
\hline
\end{tabular}

Fuente: Elaboración propia a partir de encuesta aplicada al personal administrativo docente de colegios nocturnos académicos del sistema educativo costarricense, 2017.

Por último, se consulta a los directores de los centros educativos acerca de las relaciones establecidas con sus colaboradores en el marco de la gestión ética; al respecto, uno de los primeros puntos vinculado con el clima organizacional evidencia $60,78 \%$ de una percepción "muy de acuerdo"; es decir, los administradores consideran que en términos generales todo está muy bien en las relaciones a lo interno de su centro educativo, esto aunado a 31,37\% que señala estar "más de acuerdo que en desacuerdo". Dolly (2007, citado por Luengo, 2013), señala que es "el ambiente donde una persona desempeña su trabajo diariamente, el trato que un jefe puede tener con sus subordinados, la relación entre el personal de la empresa y los proveedores" (p. 23).

Asimismo, Luengo (2013) amplía:

El clima organizacional de una institución educativa debe ser armónico, basado en buenas relaciones entre el supervisor y los docentes, así como entre los miembros del personal docente. Además de establecer relaciones favorables con el resto de los miembros de la comunidad escolar. En este orden de ideas, el ambiente de trabajo escolar debe adaptarse a las necesidades de sus miembros, o dicho de otra forma, las condiciones laborales surgen de acuerdo a las interacciones que se produzcan entre los docentes, directivos y demás miembros del plantel, asimismo, en sus relaciones con los representantes y otros actores vinculados al proceso educativo. (p. 23)

Partiendo de la respuesta de los directores y el aporte de teóricos, se evidencia que en colegios nocturnos existe un adecuado clima organizacional, por cuanto las relaciones en términos generales son armoniosas, el trato entre funcionarios es respetuoso. Es importante señalar, como parte de la información brindada por los directores, que uno de ellos considera lo siguiente: 
Sería de suma bendición si se pudiera contar con nombramientos de profesores solo para colegios nocturnos, ya que el cambio entre día y noche, considerar que los profesores por un tema de cansancio no pueden brindar el mismo rendimiento. (Aporte personal, cuestionario Directores Colegios Nocturno, nov. 2017)

Quizás, el mantener personal fijo, como señala el funcionario, podría promover y optimizar de mejor manera el clima organizacional; otra persona señala:

En nuestro caso trabajamos con compromiso y una gran ética en nuestra labor. (Aporte personal, cuestionario Directores Colegios Nocturnos, nov. 2017)

En cuanto a capacitación, aunque $82,35 \%$ de los directivos opina que se practica la igualdad, es uno de los requerimientos que más se señalan en los resultados, nótese en la siguiente tabla:

TABLA 6

Requerimientos de capacitación solicitados por los directores de colegios académicos nocturnos

1. Cursos de ética a todo el personal (incluido conserjes y vigilantes)

2. Debido proceso al personal administrativo

3. Talleres de autoestima, liderazgo y resolución alterna de conflictos

4. Charlas sobre legislación y comunicación asertiva

5. Capacitación sobre administración pública

6. Asesoramientos sobre inteligencia emocional y competencias blandas

Fuente: Elaboración propia a partir de encuesta aplicada al personal administrativo docente de colegios nocturnos académicos del sistema educativo costarricense, 2017.

Se consultó a los directivos sobre los desafíos más relevantes en cuanto a la gestión ética del centro nocturno. Al respecto, obsérvese la figura 2.

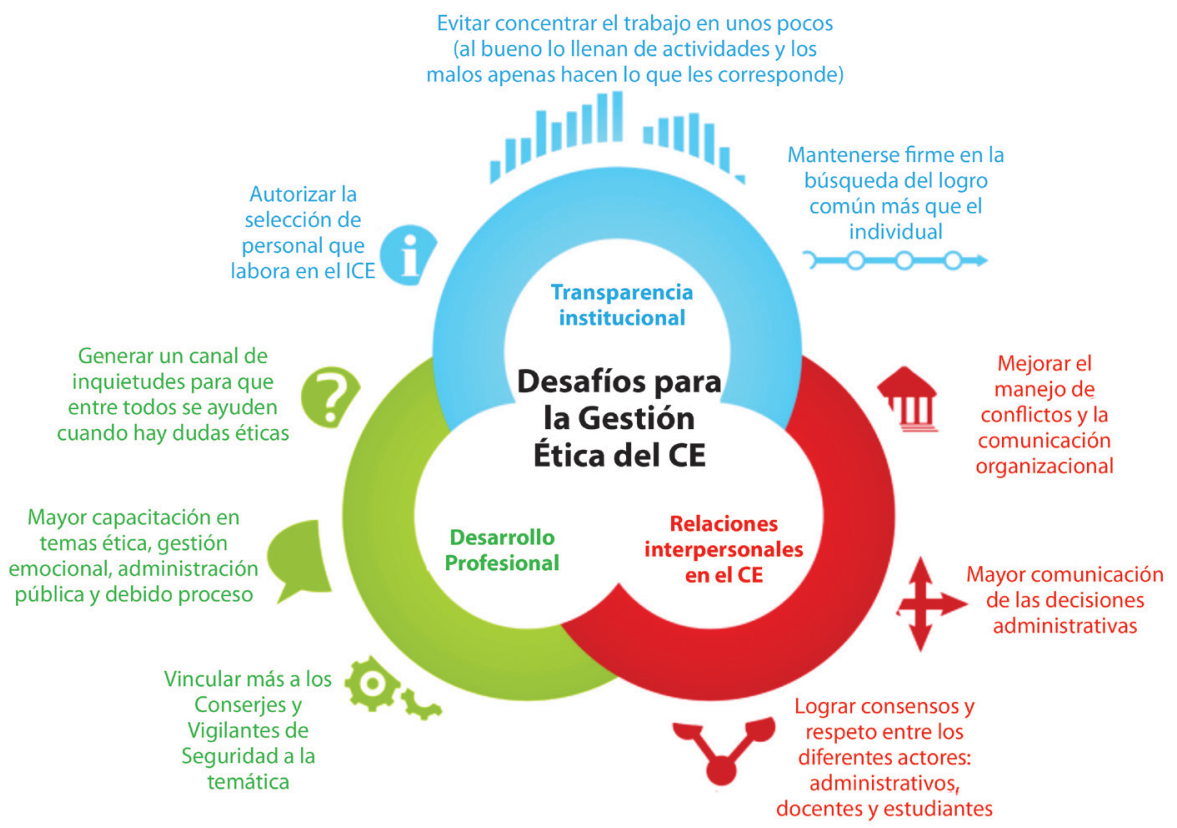

Figura 2. Principales desafíos en la gestión ética de un centro educativo nocturno.

Fuente: Elaboración propia a partir del diagrama de gobierno abierto de Le Coz y Lage (2015). 
Los desafíos en la gestión ética institucional se pueden categorizar en tres grandes áreas: transparencia institucional, relaciones interpersonales y desarrollo profesional.

En relación con la primera área, los administradores de centros educativos indican que un aspecto que facilita el logro de mayor transparencia es "mantenerse firme en la búsqueda del logro común más que el individual". Es importante señalar, parafraseando a Colorado (2016) que ser consecuente con la ética organizacional es fundamental para que dentro de las organizaciones educativas se fortalezca el compromiso de la comunidad educativa, no solo con el colegio como tal, sino con la comunidad misma, de modo que se prioricen acciones para la mejora del centro. Se exige así una gestión administrativa más eficiente y eficaz en todo sentido por parte de los directivos.

Relacionado con el criterio anterior, se indica que se debe "evitar concentrar el trabajo en unos pocos", al respecto los mismos directores evidencian, como en muchos ámbitos de trabajo, que para atender las labores prioritarias del centro se recurre a las personas que quizás sean más colaboradoras, con más experiencias o mayor compromiso, situación que podría implicar la reducción de espacios de participación a otros funcionarios que quizás estén interesados. Colorado (2016) señala:

La práctica efectiva de la ética organizacional requiere espacios de reflexión y de diálogo entre la comunidad educativa, y se relaciona estrechamente con la promoción de la comunicación, la participación y el respeto de la individualidad. [...] Se imponen, al respecto, estrategias de trabajo y formación que ayuden a superar colectivamente las situaciones (pp. 19-20).

Ante lo expuesto, se hace necesario reflexionar junto a los directores la creación de espacios de diálogo y de una gestión administrativa más democrática, donde se propicien más espacios para la toma de decisiones; una sugerencia podría ser tomar en cuenta los consejos de profesores. Dentro del área de desafíos, resulta interesante la afirmación, "autorizar la selección de personal que labora en el CE", esto por cuanto, como uno de los informantes afirmó, no existe un personal estable (en propiedad) en los centros, situación que no potencia un adecuado clima organizacional, ni es consecuente con el logro procesual de los objetivos.

Como segunda área de desafío se exponen las relaciones interpersonales en el centro educativo, dentro de este apartado se destaca la mejora en el manejo de conflictos y la comunicación organizacional. Al respecto, en concordancia con lo expresado en el cuadro 4 y 7 , el abordaje óptimo de los conflictos es primordial fortalecerlo para una adecuada gestión del centro, pues evidentemente coadyuvaría a mejorar las relaciones y la comunicación a lo interno. Fulquen (2003) señala la necesidad de atender los conflictos:

La interacción en la cotidianidad determina, en buena medida, la forma como las personas manejan las diferencias que los afectan. Esto implica un trabajo en el ámbito educativo que conlleve a trabajar en forma participativa con los diferentes actores del conflicto y desde los diferentes ámbitos en los cuales se desenvuelven, buscando asumir actitudes y comportamientos que no permitan evadir, controlar o negar la diferencia, ni mantener el control a través de la violencia; así mismo, tener claro que el problema hace parte de la vida cotidiana, que no hay que evitarlo, sino enfrentarlo y que la naturaleza y el uso del conflicto depende de cómo se aborde y se maneje como un hecho necesario para la vida y para la sociedad, como fuerza motivadora del cambio social y elemento creativo en las relaciones humanas que genera un debate en la práctica social (p. 268). 
Es así como una de las personas informante evidencia la necesidad de atender lo señalado por la autora cuando afirma:

El mayor problema es en algunos casos, el respeto que debe existir entre docentes y estudiantes. Esto porque son personas adultas y el trato o la forma con la que se les guía o habla, algunas veces esto genera polémica. (Aporte personal, cuestionario Directores Colegios Nocturnos, nov. 2017)

Queda evidenciado, entonces, la oportunidad de instancias externas de aportar a estas instituciones educativas para la mejora de su gestión ética, lo cual se une al tercer punto del área vinculada con el logro de consensos y a los diferentes actores del hecho educativo.

Por último, la tercera de las áreas se relaciona con el desarrollo profesional, el cual fue detallado en el cuadro 7, pero que se convierte en una posibilidad de proyecto de extensión para alguna instancia externa interesada en fortalecer a los colegios académicos nocturnos. Al respecto, la gestión ética del talento humano presente en la tipología del sistema educativo costarricense constituye una necesidad imperiosa de atender por parte de quienes lo administran.

\section{CONCLUSIONES}

Para Salas (2003) el centro educativo "es un tipo específico de organización, cuya especificidad estriba en las características, estructura y funciones que le correspondan, según el nivel educativo de que trate" (p. 10), desde esta perspectiva la gestión ética que se desarrolle en esa organización educativa no necesariamente tiene que ser la misma que en otra; sin embargo, existen parámetros desde la perspectiva cultural o el clima organizacional que pueden generalizarse, tal cual se presentan en este informe final de investigación.

Las percepciones acerca del conocimiento de la gestión ética, según los resultados, inciden en el quehacer práctico del administrador de centro educativo, pues es donde se concretan y donde el mismo funcionario lo evidencia. Por ende, situaciones vinculadas con la transparencia, el consenso, el diálogo, el respeto, el disenso, entre otros, se reconocen y están presentes en la gestión del centro. Lo anterior es importante, por cuanto, según lo plantea Colorado (2016), la "ética organizacional se concreta a través de códigos éticos, buenas prácticas, guías de responsabilidad social y comités de ética para ordenar y concretar sus metas y valores" (p. 17); lo cual queda demostrado en los cuadros 2, 3, 4 y 6 de este informe. No obstante, es menester señalar, como se indicó en la sección de desafíos que se deben fortalecer la transparencia institucional y el desarrollo profesional para afianzar los saberes existentes en los administradores educativos sobre la gestión ética de su centro educativo.

Ahora bien, en relación con las percepciones de los funcionarios acerca de la ética en la gestión administrativa, Ausín (2015) señala lo siguiente:

El marco general de la ética se basa en valores como: mérito, honradez, integridad, compromiso, responsabilidad, mejora continua, imparcialidad, profesionalización, fiabilidad, lealtad, transparencia, actitud innovadora, liderazgo, equidad, apego a la ley, interés colectivo, objetividad, confidencialidad, austeridad, neutralidad, promoción medioambiental, entre otros. (p.20)

Lo anterior se evidencia en los cuadros 3 y 4, donde se indican las percepciones de los directivos en concordancia con postulados teóricos; por ejemplo, más de la mitad de los informantes señalan que hay acompañamiento para el cumplimiento del código de ética; $90 \%$ señala que se viven los valores éticos 
día a día en el centro educativo y se utiliza el diálogo y el consenso como medios para evitar el conflicto $y$, en términos generales, los funcionarios evidencian normas y valores éticos.

Al igual que la conclusión del objetivo ya expuesto, en este caso es necesario reforzar mediante el desarrollo profesional el conocimiento de los diferentes funcionarios de los centros educativos, pues tal como uno de ellos lo señala, es necesario "un taller de ética, ya esta dirección está coordinando con personeros externos en donde nos impartirán un taller de reforzamiento en cuanto a ética y profesionalismo se refiere" (aporte personal, cuestionario Directores Colegios Nocturno, noviembre 2017).

En cuanto a las relaciones de los actores educativos respecto a la ética en el centro educativo, en términos generales el cuadro 6 muestra porcentajes bastante altos de percepciones que generan una convivencia adecuada, ética y armoniosa. Esto puede traducirse, aunque sin generalizar, en una toma de decisiones compartidas en los centros educativos, toda vez que se convive, se aprecia, se siente y se comparten elementos comunes en los actores educativos de la instancia estudiada.

Por último, un punto por resaltar es el desafío en cuanto a elevar la percepción de mejora del componente "clima organizacional" de modo que se alineé con las restantes percepciones. Ahora bien, elevar el rubro al nivel de los restantes, potencia que desde la "cabeza" del centro educativo se les otorgue una importancia a las relaciones entre las distintas personas que interactúan para que el colegio nocturno, al unísono, se visualice como una organización educativa que cumple a cabalidad con una gestión ética a la cual le importa no solo la persona que llega a trabajar o estudiar, sino la colectividad y el beneficio de la mayoría.

A partir de los datos recuperados es necesario que los administradores de los colegios académicos nocturnos gestionen procesos de desarrollo profesional vinculados con la mejora de la gestión ética institucional no solo en el personal docente, sino también en administrativos docentes y administrativos. Por su parte, el administrador del centro debe generar recursos logísticos y físicos para el fortalecimiento de la ética profesional en el desempeño de las funciones de sus colaboradores; así como el conocimiento en administración pública y no solo en administración educativa; situaciones que inciden en una mejora en la gestión ética de los colegios nocturnos.

La Administración Educativa, como disciplina de las ciencias de la educación, tiene en la gestión del centro, particularmente en la gestión ética del mismo, un foco de estudio importante desde el campo investigativo y crítico, debido a los retos que enfrenta la educación en la actualidad.

Tal como señala Salas (2003), "es indispensable elevar la calidad de la educación, razón por la cual elevar la capacidad de gestión de la organización educativa se vuelve uno de los principales problemas por resolver por parte de los teóricos e investigadores" (p. 15).

\section{REFERENCIAS}

Ausín, T. (2015). Ética pública para generar confianza. Revista Vasca de Gestión de Personasy Organizaciones Públicas, (9) 30-39. Recuperado de https://www.euskadi.net/r61-s20001x/es/t59aWar/t59aMostrarFicheroServlet?t59aldRevista=3\&R01HNoPortal=true\&t59aTipoEjemplar=R\&t59aSeccion=51\&t59aContenido $=3 \&$ t59aCorrelativo $=1 \&$ t59aVersion $=2 \&$ t59aNumEjemplar $=9$

Carmona, O. (2015). Gestión de los conflictos laborales en los centros educativos de educación secundaria desde la normativa vigente. Revista Gestión de la Educación, 5 (2) 69-97. doi: http://dx.doi. org/10.15517/rge.v5i2.19943

Colorado, S. (2016). La ética organizacional en los centros educativos. Análisis de concepciones y práctica educativas. Revista Perspectiva Educacional, 56 (1) 127-146. doi: 10.4151/07189729-Vol.56-Iss.1-Art.477 
Cortina, A. (2004). Construir confianza. Ética de la empresa en la sociedad de la información y las comunicaciones. Madrid: Trotta.

Enríquez, A., De la Campa, S., Valdés, V., Navarrete, M., Lemus, P., Vargas, J.M. \& Dubrin, A.J. (2014). Taller de ética: para cursos por enfoques por competencias. México: Pearson.

Fulquen, M. (2003). Los conflictos y las formas alternativas de resolución. Revista Tabula Rasa, (1) 265-278. Recuperado de http://www.revistatabularasa.org/numero-1/Mfuquen.pdf

Gentili, P. (2000). Educación y ciudadanía: la formación ética como desafío político. En Gentili, P. (coord). Códigos para la ciudadanía: La formación ética como práctica de la libertad. Buenos Aires: Santillana.

Guillén, M. (2006). Ética en las organizaciones: Construyendo confianza. Madrid: Pearson.

Le Coz, A. \& Lage, C. (2015). Diagrama de gobierno abierto de Armel Le Coz \& Cyril Lage [Diagrama]. Recuperado de https://commons.wikimedia.org/wiki/File:Open_government_-_spanish_1.png

Luengo, Y. (2013). Clima organizacional y desempeño laboral del docente en centros de educación inicial. (Tesis maestría). Universidad del Zulia, Venezuela. Recuperada de https://es.slideshare.net/ ronaldaraujo10/clima-organizacional-y-desempeo-laboral-del-docente

Martín-Moreno, Q. (2007). Organización y dirección de centros educativos innovadores. El centro educativo versátil. Madrid: McGraw-Hill.

Orden, V. (27 noviembre 2014). Simposio 3.1 Ética y responsabilidad social del líder educativo. En Desarrollo de las instituciones y su incidencia en la innovación de la docencia [archivo digital]. (9-11). Canal UNED.

Pereda, C. (2009). Sobre la confianza. Barcelona: Herder.

Pozner, P. (2015). El Directivo Docente como Líder de la Gestión Educativa. Recuperado de http://186.113.12.182/catalogo//dlfile.php?id=32364

Quero, Y., Mendoza, F. \& Torres, Y. (2014). Comunicación efectiva y desempeño laboral en educación básica. Revista Científica de Ciencias Gerenciales 27 (9) 22-35. Recuperado de http://www.redalyc.org/ html/782/78230409001/index.html

Salas, F. (2000). Ética y administración educativa: retos y desafíos en la coyuntura actual. Revista Educación, 24 (2) 189-200. Recuperado de https://revistas.ucr.ac.cr/index.php/educacion/article/ view/484/473

Salas, F. (2003). La administración educativa y su fundamentación epistemológica. Revista Educación, 27(1) 9-16. Recuperado de https://revistas.ucr.ac.cr/index.php/educacion/article/download/3794/3667

Vásquez, G. (2013). Análisis comparativo entre los principios éticos de los directores de educación primaria y secundaria del Circuito 05 de Naranjo de la Dirección Regional de San Ramón, el Código de Ética del Colegio de Licenciados y el Manual Descriptivo de Puestos del MEP para una propuesta de un código de ética. (Tesis de maestría inédita). Universidad de Costa Rica, Costa Rica. 